Resultados: A análise por microscopia eletrónica permitiu identificar diferenças no tamanho das partículas consoante a amostra considerada, tendo-se constatado um tamanho inferior quando considerado o dente incisivo (de 1,01 mm- 211,84 $\mu \mathrm{m}$ para 158,32-906,45 $\mu \mathrm{m}$ ). Relativamente à morfologia, em ambas as amostras, esta é idêntica, com distinção de uma camada externa correspondente ao esmalte e uma camada interna correspondente à dentina. Contudo, a camada externa no incisivo apresentou mais poros, sendo estes mais definidos e em maior número. A análise por EDS demonstrou uma semelhança em termos de elementos químicos presentes em ambas as camadas, embora a camada interna na amostra obtida do incisivo tenha apresentado uma maior quantidade de cálcio. Conclusões: A espessura dentinária parece determinar as diferenças topográficas e químicas detetadas. No entanto, o desenvolvimento de estudos adicionais torna-se pertinente no sentido de esclarecer a influência que esta característica poderá desempenhar no sucesso da regeneração óssea.

http://doi.org/10.24873/j.rpemd.2019.12.601

\section{\#142 Comparação topográfica e química de particulados dentinários com e sem resina composta}

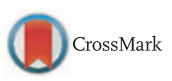

Daniela Filipa dos Santos Silva*, Mariana Azevedo Melo, Sandra Carvalho, Inês Côrte-Real, Paula Vaz, João Carlos Sampaio Fernandes

Departamento de Física da Universidade de Minho, Faculdade de Medicina Dentária da Universidade do Porto

Objetivos: Vários biomateriais têm sido desenvolvidos para promover a regeneração óssea, sendo que, a possibilidade de utilização de dentes extraídos como um material de enxerto autólogo tem sido proposta. O dispositivo Smart Dentin GrinderTM (Calvo-Guirado JL et al., 2018) foi concebido com este propósito permitindo o fabrico do material de enxerto por trituração dentária. Contudo, previamente a este procedimento um dos cuidados clínicos protocolados pressupõe a remoção prévia de qualquer material artificial da superfície dentária, como a resina composta. Como tal, este estudo tem como objetivo avaliar a existência de diferenças na topografia e composição química de particulados dentinários, obtidos após a moagem de dentes para posterior utilização como material de enxerto, consoante a presença ou ausência de resina composta. Materiais e métodos: Para a realização deste estudo foram utilizados dois dentes incisivos centrais superiores, um deles íntegro (sem qualquer material artificial adicionado) e o outro restaurado com resina composta. Os dentes foram processados com a Smart Dentin Grinder ${ }^{\mathrm{TM}}$, segundo o protocolo do fabricante. Para este processamento dentário foi considerado uma trituração de 3 segundos, seguida de uma fase de vibração de 20 segundos para que fossem obtidas partículas entre os 300 e $1200 \mu \mathrm{m}$. A análise da morfologia do particulado dentinário obtido foi efetuada por microscopia eletrónica de varrimento (NanoSEM - FEI Nova 200 (FEG/SEM)). A composição química das amostras foi identificada através de EDS (EDAX - Pegasus $\mathrm{X} 4 \mathrm{M})$. Resultados: Pelas análises de microscopia eletrónica constatou-se que o tamanho das partículas na amostra com resina composta $(1,37 \mathrm{~mm}-300,67 \mu \mathrm{m})$ é menos uniforme comparativamente à amostra íntegra (158,32-906,45 $\mu \mathrm{m})$, existindo uma maior variabilidade relativamente ao tamanho das mesmas. Em ambas as amostras são detetáveis os túbulos dentinários, mas nas zonas com resina composta tornam-se menos percetíveis (parecendo estarem recobertos) e, por isso, aparentando serem menos profundos. A análise da composição química na amostra com resina composta detetou uma expectável maior quantidade de carbono. Conclusões: A manutenção de resina composta nos dentes selecionados para serem processados em material de regeneração óssea autógena condiciona alterações topográficas e químicas, que devem ser exploradas em estudos futuros, no sentido de compreender se as mesmas poderão interferir no processo de osteointegração. http://doi.org/10.24873/j.rpemd.2019.12.602

\section{\#144 Terapias de extração parcial: revisão sistemática e meta-análise}

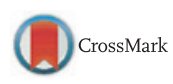

Miguel Pimenta*, Tiago Nunes, Francisco Caramelo, João Paulo Tondela

Faculdade de Medicina Universidade de Coimbra

Objetivos: Após a extração dentária desencadeiam-se mecanismos fisiológicos multifatoriais que conduzem a reabsorção óssea e remodelação alveolar. Em zonas anteriores estas alterações tridimensionais do rebordo alveolar interferem frequentemente com o resultado estética das reabilitações implanto-suportadas. Existem diversas técnicas desenvolvidas para minimizar as alterações tecidulares pós-extração e compensar as alterações dimensionais, apesar de nenhuma técnica cirúrgica ou nenhum material previna completamente essas alterações. As terapias de extração parcial foram recentemente desenvolvidas com o objetivo de prevenir a reabsorção da tábua óssea vestibular.<br/>Este trabalho pretende fazer uma revisão sistemática e meta-análise para a avaliação da perda de osso em implantes colocados em alvéolos sujeitos às técnicas de extração parcial. Materiais e métodos: Realizou-se uma pesquisa bibliográfica na PubMed/MEDLINE e na Cochrane Library com a seguinte chave de pesquisa: ('socket-shield' OR "root membrane") AND (implant OR dental OR ridge OR esthetics), usando como filtros publicações em inglês ou português até ao Maio de 2019. Não foram feitas restrições sobre o tipo de publicação. Foi realizada uma análise estatística utilizando o pacote "Metafor". Resultados: Obteve-se um total de 49 artigos dos quais foram selecionados 8 para leitura integral, após exclusão dos duplicados e leitura do título e resumo. Desses artigos, sete foram incluídos para esta revisão sistemática. Os estudos incluíram um total de 431 pacientes e 511 implantes colocados de acordo com as técnicas de extração parcial. A meta-análise mostrou uma perda de osso de 0,29 mm; 95\% CI: 0,05 a 0,52 mm. Conclusões: Dentro das limitações desta revisão, pode ser concluído que as terapias de extração parcial em conjunto com a colocação de implantes imediatos podem prevenir eficazmente a perda de osso marginal e consequentemente, manter a estética dos tecidos moles.

http://doi.org/10.24873/j.rpemd.2019.12.603 